\title{
LIBERDADE: O BAIRRO, O NOME, O LUGAR E A INTENCIONALIDADE DE SEU GUIA TURISTICO
}

\author{
Vitoria Maria Santos* \\ Airton José Cavenaghi**
}

RESUMO: Este artigo tem como objetivo geral a análise de particulares do bairro da Liberdade, localizado na cidade de São Paulo, pela comparação de três diferentes suportes documentais: seu guia turístico, o patrimônio cultural existente na região e imagens produzidas in loco desses mesmos patrimônios. O método utilizado foi o da revisão bibliográfica, associada à comparação documental e visitas observacionais in loco, para assim analisar a construção de uma espécie de imaginário turístico, associado à presença da etnia japonesa no local. Como resultados observa-se que a legitimazação do processo de turistificação da região, estrutura-se na representação da documentação produzida pela administração pública, que se ampara na reprodução do imaginário constituído pelo patrimônio cultural presente, seja em suas edificações ou mesmo na execução das atividades cotidianas locais.

PALAVRAS-CHAVE: Turismo; Liberdade; Turistificação; Guia turístico; Etnia japonesa.

\section{THE LIBERDADE DISTRICT: THE DISTRICT, NAME, PLACE AND INTENTIONALITY OF ITS TOURIST GUIDE}

ABSTRACT: Details of the São Paulo district called Liberdade are analyzed by comparing three different documents: tourist guide, the cultural heritage in the region and photos of the heritage produced on the spot. A bibliographic review, associated with a comparison of documents and visits, was employed to analyze the construction of a touristic imaginary stance involving Japanese ethnicity. Results show that the legitimation of the region's tourist role is structured on the documents produced by the public administration, based on the reproduction of the imaginary made up by the current cultural heritage consisting of buildings or local daily activities.

KEY WORDS: Tourism; Liberdade; Touristification; Tourism guide; Japanese ethnicity.

\footnotetext{
${ }^{*}$ Graduanda do curso de Turismo Universidade Anhembi Morumbi (UAM-SP), Brasil.

** Docente do Mestrado e Doutorado em Hospitalidade Universidade Anhembi Morumbi (UAM-SP), Brasil.

E-mail: acavenaghi@gmail.com
} 


\section{INTRODUÇÃO}

Esse artigo tem como objetivo geral a análise de aspectos do processo de turistificação do bairro da Liberdade, localizado no centro da cidade de São Paulo. Trata-se da exposição da pesquisa realizada, como complemento a outra maior intitulada "Turismo e legado étnico na cidade de São Paulo", em desenvolvimento. Por aquela ser classificada como "pesquisa auxiliar", pode ser definida como uma coleta documental, pois procura elucidar algumas questões ainda em aberto sobre $o$ desenvolvimento histórico do bairro da Liberdade. Entre as questões que motivaram o desenvolvimento desse artigo encontram-se: Qual o real significado do nome do bairro? De que maneira se consolidou o imaginário turístico do local ligado à presença da etnia japonesa?

Para tanto, trata-se de um artigo com pesquisa de abordagem qualitativa com caráter exploratório, a partir do uso de recursos de análise de imagens e documentações específicas (bibliográfica, documentação histórica etc.). Tal proposição metodológica foi escolhida de maneira a direcionar a interpretação das possibilidades de formação do olhar turístico e de como o mesmo é influenciado pela ambientação do local, artificialmente construída.

O olhar do turista ampara-se, e muito, na ambientação do local visitado. Carlos Lemos (1989) relembra que a atratividade de um local, ou seja, a formação de um fluxo turístico está vinculada diretamente à compreensão e divulgação dos patrimônios culturais locais.

A história do surgimento do bairro Liberdade tem início com a divisão do distrito da Sé, em meados de 1883, onde ocorreu a divisão entre norte e sul (onde se localiza o bairro atualmente). Entretanto, a denominação do nome do bairro tem início em meados de 1800, com a construção da forca que situava- se ao lado do pelourinho, onde é conhecido como Largo ou rua da Forca. Desde 1834, o local onde se localizava um chafariz que abastecia todo o bairro da Pólvora, segundo Ata da Câmara, chamava-se praça da Liberdade. Posteriormente, com a lei Áurea, em 1950, e o fim da pena de morte no Brasil, o Largo da Forca começou a ser denominado de largo da Liberdade e posteriormente toda a região que foi dívida em meados de 1883, Liberdade (BRUNO, 1953); (DICK,1997); (GUIMARÃES, 1968). 


\section{METODOLOGIA DE PESQUISA}

A questão de pesquisa que se formou refere-se a pensar: de que maneira o bairro da Liberdade passou a constituir-se como um lugar turístico na cidade de São Paulo?

Para o desenvolvimento dessa análise, buscou-se, inicialmente, a construção do referencial bibliográfico, associando essas leituras, com uma série de vistas in loco, entre os meses de junho e novembro do ano de 2017 , de maneira a perceber a herança cultural deixada pela presença da etnia japonesa no local.

Analisa-se, também, a produção de "guias turísticos" para o local, que ao serem organizados para "facilitar" a visitação turística, acabam por legitimar um imaginário artificialmente construído, reproduzindo valores e significados que não expressam o real desenvolvimento histórico da região. Optou-se, neste aspecto, pelo uso do mais recente "Guia da Cidade de São Paulo", confeccionado no ano de 2017, pela prefeitura municipal, e distribuído gratuitamente à população e aos visitantes.

\subsection{INÍCIO DAS DISCUSSÕES}

Em meados de 1900, o Brasil estava em fase de desenvolvimento econômico, principalmente na agronomia e precisava de mão de obra para as lavouras e cafezais, enquanto que o Japão passava por uma crise econômica também maximizada por acelerado crescimento populacional. Com isso, o trabalho escravo começou a ser substituído pelo trabalho de imigrantes japoneses que vinham para o interior de São Paulo, em busca de trabalho nas fazendas, devido à crise no Japão (OSAKI, 2007).

$\mathrm{Na}$ região de fixação desses imigrantes, relembra Araújo, era " [...] quase totalidade formada de prédios de construção antiga, o que facilita a constituição de moradias coletivas" (ARAUJO, 1940, p. 237). A presença dessa coletividade pode ter ajudado a constituir maior identidade étnica ao local, ou seja, a proximidade dos núcleos familiares instituiu necessidades próximas e, assim, o espaço habitado passa a representar e propagar o imaginário coletivo existente.

O núcleo de moradia dos japoneses teve início na rua Conde de Sarzedas, pois havia muitas pensões e porões e, cada vez mais, chegavam mais japoneses em 
São Paulo devido à Segunda Grande Guerra Mundial. Por volta de 1960, a polícia brasileira começou a dispersar os japoneses de lá para outras ruas das imediações, com isso o bairro Liberdade se tornou oficialmente japonês. Com o aglomerado de imigrantes japoneses no bairro, em pouco tempo as construções e a arquitetura se tornaram parecidas com as do Japão, e posteriormente o bairro foi recebendo também imigrantes chineses e coreanos, transformando o bairro em um centro oriental, e não mais japonês (BOCCI, 2008).

O "tornar parecido com a arquitetura japonesa" institui a perpetuação de uma memória coletiva associada ao usuário do espaço. Neste caso, elementos de segregação social e política não foram mediatamente identificados, mas situações de segregação econômica, ou seja, o bairro era o mais próximo do centro com baixos preços nos aluguéis.

\subsection{A TURISTIFICAÇÃO DO BAIRRO LIBERDADE}

O processo de turistificação ocorre quando um espaço é apropriado pelo turismo e, por meio disso, há o direcionamento das atividades do local para o atendimento de visitantes, alterando a configuração em função dos interesses do mercado, pois haverá consumo de bens, serviços e atrativos (ISSA E DENCKER, 2006). No caso do bairro da Liberdade, este processo pode ser datado ao início do ano de 1973, quando a secretaria de turismo municipal foi ativada no bairro para incentivar os lojistas da região em um plano paisagístico. Pretendia-se transformar o bairro em uma "China Town" com a instalação de luminárias ocidentais e bambus ao invés de árvores nas ruas, restaurantes típicos, casas noturnas de karaokê e a realização de festas e manifestações culturais do oriente, para que o bairro se tornasse um núcleo de cultura oriental e com isso um atrativo turístico para os visitantes nacionais e estrangeiros (GUIMARÃES,1968). 


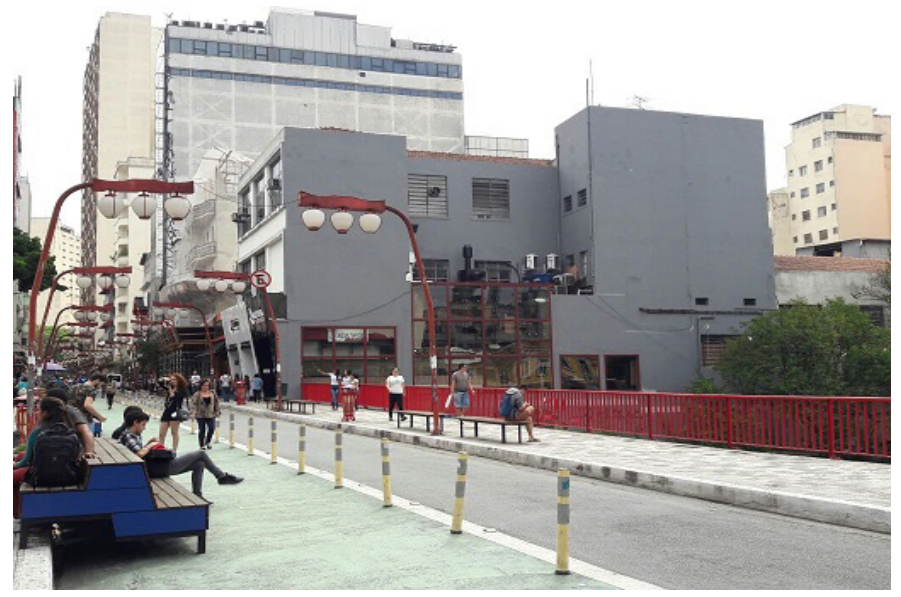

Figura 1. Avenida da Liberdade.

Fonte: Autores, 2018

$\mathrm{Na}$ Figura 01 nota-se que a apropriação de elementos característicos da cultura japonesa, inserindo-se na paisagem que ajudam a legitimar o cenário turístico. Embora originalmente, na época da presença inicial da etnia japonesa, não houvesse características claras e distintas dessa ocupação; algo que referenciasse diretamente a presença da etnia japonesa; essa mesma presença é legitimada pela estruturação de patrimônios culturais associativos a ela. A instalação das luminárias em estilo oriental, existentes nos dias atuais no local, por exemplo, denota elementos da padronização de um imaginário necessário a constituir e direcionar o processo de turistificação do local.

O local para ser turístico também necessita de ter facilitado o acesso de pessoas. Precisa, também, do caminho seguro que possibilite um fluxo cada vez maior de turistas e assim, indiretamente, legitimar a memória artificialmente instituída. 


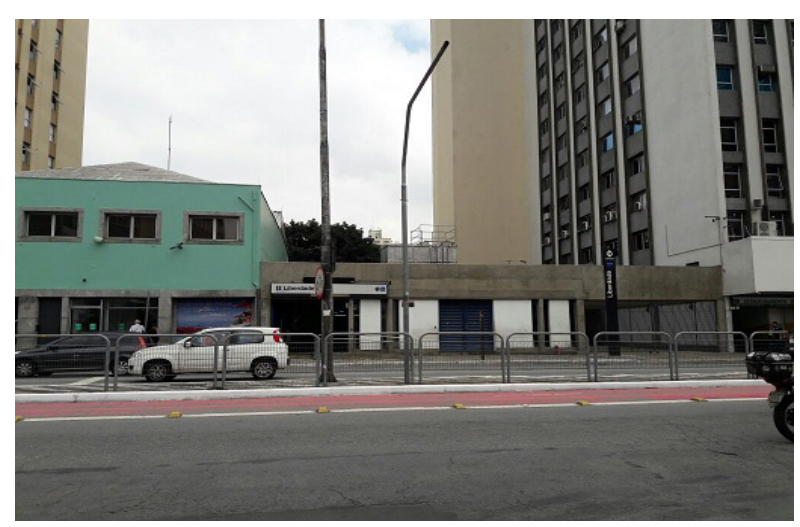

Figura 2. Avenida da Liberdade e o acesso ao metrô.

Fonte: Autores, 2018

Na Figura 2 nota-se a entrada do metrô Liberdade, inaugurado no ano de 1975. Nessa possibilidade de deslocamento, criada com a presença do metrô, também ocasionou a inauguração oficial da "Feira Oriental da Liberdade", que teve início ao mesmo tempo da presença do sistema de transporte do metrô. Esse fato é interessante e reforça as características de turistificação atribuídas ao local. Já havia um imaginário instituído e agora se tornava, de certa maneira, mais legitimado, com a possibilidade de um maior deslocamento de pessoas; leiam-se possíveis turistas para a região.

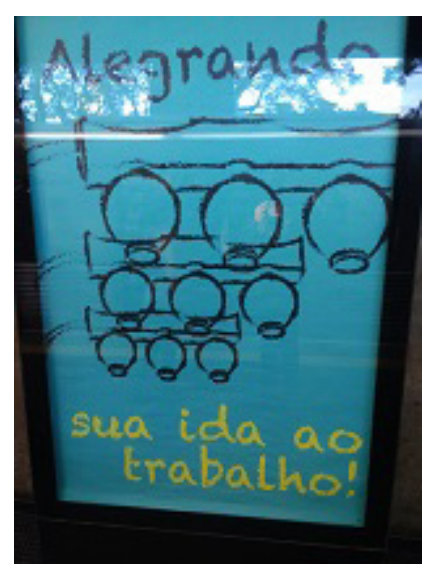

Figura 2B. Letreiro indicativo, estação de metrô Bresser. Fonte: Autores, 2018 
Na Figura 2B nota-se, associado à análise anterior, que o imaginário turístico presente no patrimônio cultural associado ao bairro da Liberdade está presente, neste caso específico, como uma espécie de propaganda nas estações do metrô paulistano, incorporando um significado de lazer necessário aos usuários do serviço de transporte coletivo. Nota-se assim que a frase apresentada "Alegrando, sua ida ao trabalho" propõe uma ludicidade associada à utilização do patrimônio cultural incorporado pela memória coletiva.

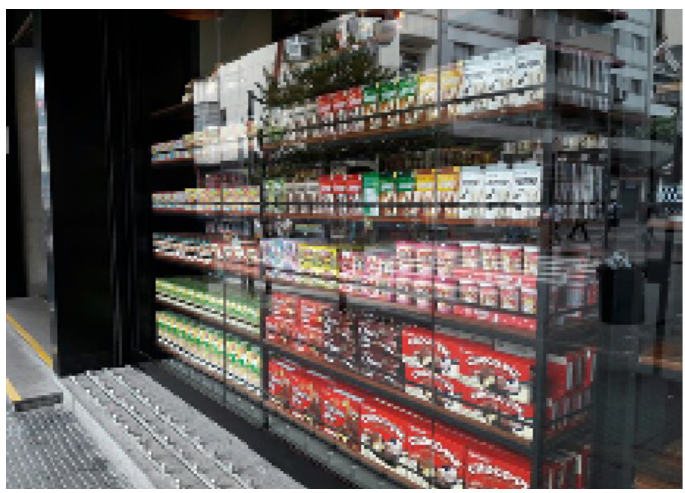

Figura 3. Fachada de loja na Liberdade.

Fonte: Autores, 2018.

No bairro da Liberdade a presença de comércios que vendem produtos eletrônicos, roupas e alimentos importados atrai muitos visitantes pela sua variedade de lojas. A Figura 03 mostra a vitrine de uma loja de alimentos importados do bairro, onde alguns produtos possuem ideogramas japoneses. Este tipo de comércio traz uma identidade muito forte para o bairro, pois os visitantes e turistas colocam na sua lista de opções procurar no bairro da Liberdade quando estão à procura de algum produto específico que seja mais difícil de encontrar em lojas comuns. Claro que muitos dos produtos não são exclusivamente relacionados à etnia japonesa, mas estão nos mesmos locais de venda daqueles produtos, incorporando e ampliando os significados e a memória coletiva propagada. Não há uma separação étnica explícita, uma fronteira demarcada, mas uma espécie de proximidade entre os produtos. Este fato pode ajudar a demonstrar a fusão cultural existente entre aquele que chega, o imigrante e o habitante do local da chegada. 


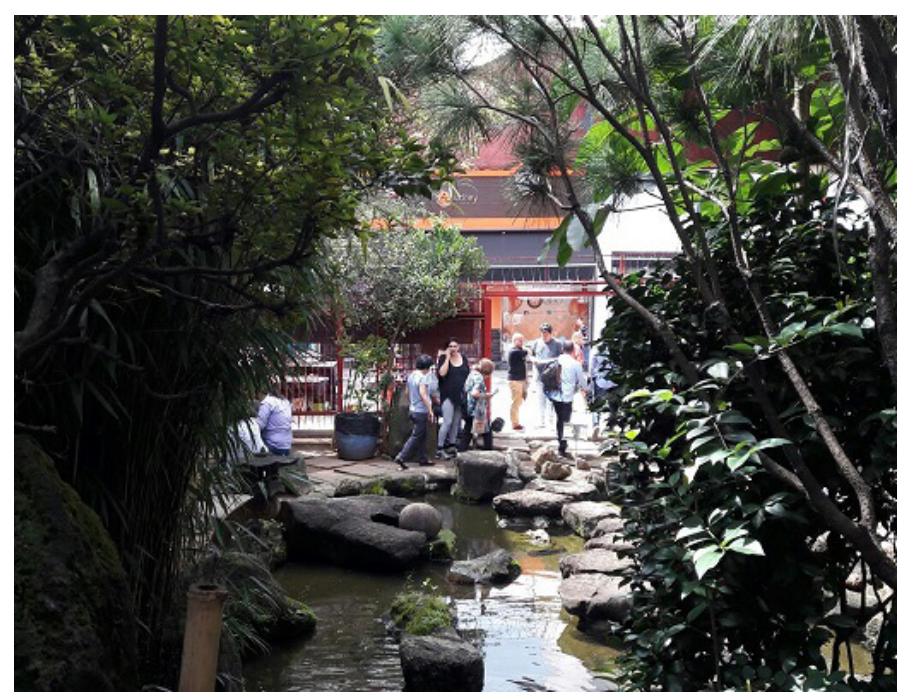

Figura 4. Jardim Oriental.

Fonte: Autores, 2018.

A Figura 4 mostra o jardim Oriental, que fica localizado na rua da Glória. Um local de ambiente simples, rústico e tranquilo, um espelho d'água forma um lago com carpas coloridas, grandes pedras e pés de bambus no seu entorno atrai famílias e muitos turistas para apreciar este cenário natural e registrar fotografias. Há também aos sábados a venda de diversas comidas típicas da gastronomia japonesa. Lá a natureza é apresentada como conquistada e confinada no espaço urbano. A técnica associada à sua construção mostra a racionalização científica, presente na artificialidade do jardim. O patrimônio cultural é representado e associado diretamente à memória formativa da etnia japonesa.

Atualmente, o bairro da Liberdade ainda possui a identidade de um bairro tradicional japonês, pelos detalhes do bairro que estão presentes até hoje como a decoração das ruas por meio das luminárias ocidentais, fachadas com ideogramas japoneses, restaurantes típicos de comida oriental, feiras de artigos japoneses. Além disso, é um local que reforça sua identidade por meio de eventos fixos que ocorrem durante o ano, como ano novo chinês, Hanamatsuri (festival das flores), campeonato de sumô da Liberdade, Tanabata Matsuri (festival das estrelas), Toyo Matsuri (festival oriental) e Moti Tsuki (festival de final do ano). 


\section{ANALISADO O "GUIA DA CIDADE DE SÃO PAULO"}

Para "amparar" a visitação turística, a prefeitura da cidade de São Paulo confeccionou e distribui um guia de bolso para visitantes ou não da cidade de São Paulo.

Confeccionado em uma tiragem 27 mil exemplares, sua última edição data de julho de 2017, ou seja, é o modelo que atualmente reproduz a visão dos gestores administrativos, em relação à produção do imaginário turístico paulistano. Todos seus textos são bilíngues, português e inglês, incluindo-se as informações de localização existentes nos mapas.

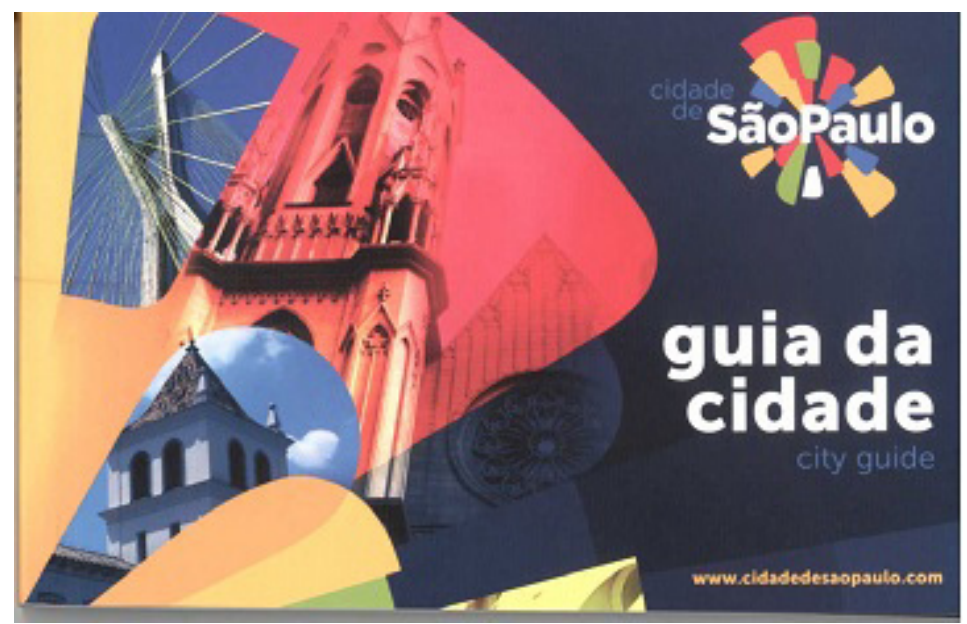

Figura 5. Capa "Guia da Cidade", 2017

Com grande portabilidade $(15 \mathrm{~cm} \times 10 \mathrm{~cm})$, o guia pode ser considerado uma publicação de bolso, e apesar da enorme variedade de aplicativos para dispositivos móveis existentes na atualidade, o guia pode ser observado, não raro, nas mãos de transeuntes, principalmente nas ruas da região Central da cidade, observação que foi percebida in loco durantes as visitas realizadas para o desenvolvimento dessa pesquisa.

A distribuição do guia não é feita aleatoriamente, ele é encontrado nas denominadas CIT (Centrais de Informações Turísticas) ou mesmo em hotéis e outros estabelecimentos comerciais, principalmente na região Central da cidade. 
Com uma tiragem de 27 mil exemplares é significativo que seja usado e assim, suas informações passam a servir de instrumento de legitimação do poder gerenciador da cidade.

Os mapas apresentados incorporam diversas regiões e encontram-se ao final do volume para serem destacados e usados separadamente do guia, fato que facilita ainda mais sua portabilidade e, consequentemente, a reprodução do imaginário pensado na época de sua confecção.

O mapa apesar de ser um objeto com características técnicas bem definidas e associadas à sua legitimidade como divulgador de ideias é um produto cultural e dessa maneira deve ser visto (CAVENAGHI, 2006).

Qualquer produção cultural carrega os valores e saberes de seu produtor e dessa forma deve ser analisado e criticado.

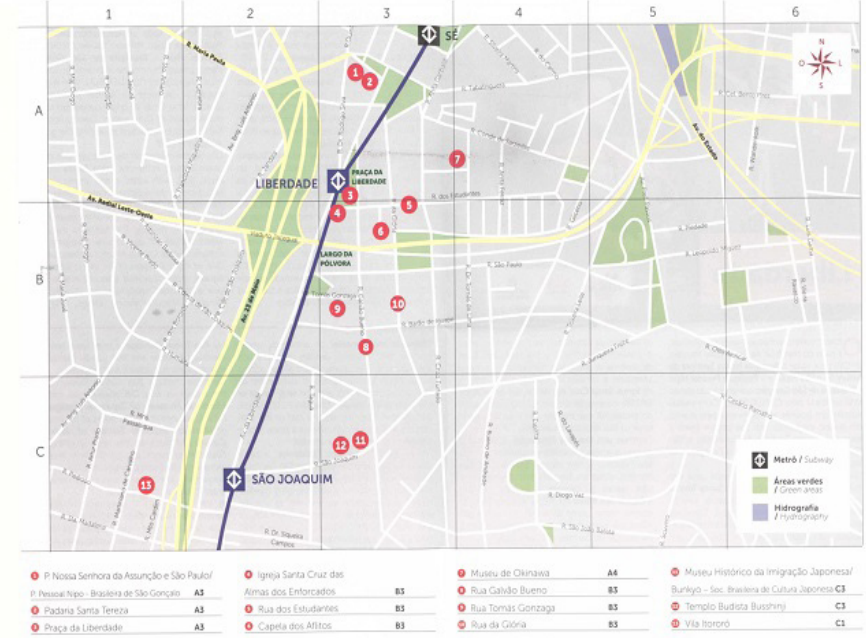

Figura 06: Mapa destacável da Liberdade $(26,5 \mathrm{~cm}$ x $19 \mathrm{~cm})$ : impressão sobre papel. Fonte: (GUIA, 2017)

No mapa, representado na Figura 06, nota-se a preocupação de seus autores em destacar as "Chamadas Atrações Imperdíveis", aquelas que são selecionadas para atuarem como veículos indutores do imaginário turístico que se quer caracterizar em relação ao local mapeado. Claro que associado a isso, os patrimônios históricos 
existentes na indicação cartográfica, também são apresentados, embora esses sirvam de fundo a proposta de divulgação da atração referenciada.
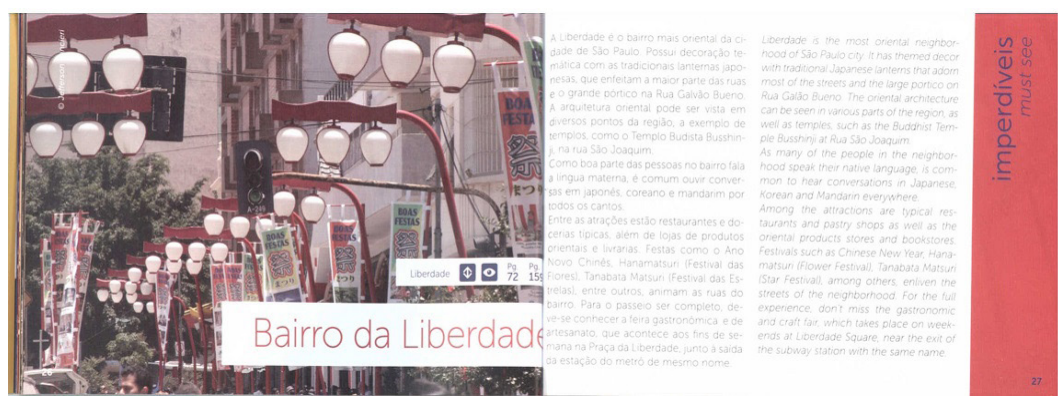

Figura 7. Bairro da Liberdade: imperdíveis.

Fonte: (GUIA, p. 27, 2017)

Nota-se na descrição do texto do guia que o produtor do objeto direciona os interesses que devem ser acatados pelo usuário. Na fala do texto é expressa diretamente essa preocupação.

A Liberdade é o bairro mais oriental da cidade de São Paulo. Possui decoração temática com tradicionais lanternas japonesas, que enfeitam a maior parte das ruas e o grande pórtico da Rua Galvão Bueno. A arquitetura oriental pode ser vista em diversos pontos da região, a exemplo de templos, como o Templo Budista Bussshinji, na rua São Joaquim. Como boa parte das pessoas no bairro fala a língua materna, é comum ouvir conversas em japonês, coreano e mandarim por todos os cantos. [...] Para o passeio ser completo, deve-se conhecer a feira gastronômica e de artesanato, que acontece aos fins de semana na Praça da Liberdade, junto à saída da estação do Metrô de mesmo nome. (GUIA, 2017, p. 27).

O texto de apresentação do bairro no GUIA (2017) define as qualificações que o local deve propagar, ou seja, a possibilidade de encontrar as pessoas falando "[...] a língua materna" e que a "decoração temática enfeita a maior parte das ruas", ou mesmo que "a arquitetura oriental pode ser vista em diversos pontos da região". Nos resultados das visitas in loco realizadas, nada disso pode ser observado ou confirmado. Há grande variedade de etnias que habitam o lugar e na atualidade, 
o que pode se observar é, além da presença de migrantes nacionais, a presença de imigrantes sul-americanos e africanos, sendo que a questão das línguas maternas orientais não é mais um fator preponderante para sua identificação étnica. A decoração temática e a arquitetura são bem limitadas às ruas Galvão Bueno e em parte da rua da Glória, ou seja, não é maioria nas ruas do bairro, pensando-se na análise da delimitação geográfica estabelecida pelo mapa analisado para este estudo.

Observa-se assim que aquilo que é propagado como um elemento identificador do turista com o bairro, na realidade é a reprodução e perpetuação do mito fundador do local. Neste aspecto o resultado a ser percebido é que, ao manterse esse tipo de postura, com o uso de uma documentação oficial de referência, organiza-se e controla-se o fluxo turístico, reproduzindo-se as necessidades de uma elite administrativa.

Na Figura 08 é possível notar outros elementos ligados às necessidades desse grupo gestor.
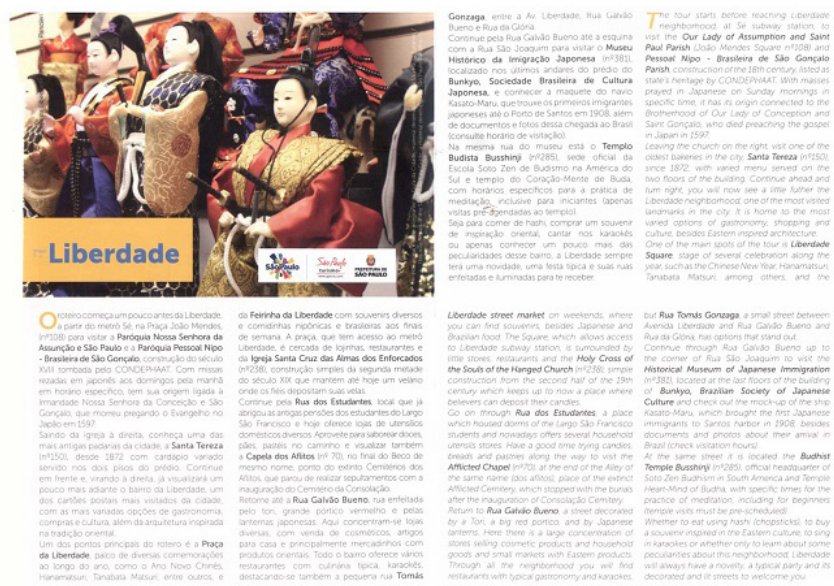

Figura 8. Verso do mapa descartável da Liberdade $(26,5 \mathrm{~cm}$ x $19 \mathrm{~cm})$ : impressão sobre papel. Fonte: (GUIA, 2017).

As informações existentes no verso do mapa do bairro da Liberdade apresentam roteiro a ser seguido a pé pelo visitante. Observa-se que é uma sugestão ao turista para organizar a sua visita. Embora se proponha a isso, a imagem de 
referência para a apresentação do roteiro passa a sugerir a questão da presença da etnia japonesa no lugar, reforçando a ideia do mito fundador, negligenciando a atual realidade do local, ou seja, sua multiplicidade étnica e não apenas a oriental. $\mathrm{O}$ restante do textual reproduz as características desse imaginário, tais como

Feirinha da Liberdade com souvenirs (sic) diversos, e comidinhas nipônicas [...]; Rua Galvão Bueno, rua enfeitada pelo tori, grande pórtico vermelho e pelas lanternas japonesas [...]; Liberdade sempre terá uma novidade, uma festa típica e suas ruas enfeitadas e iluminadas para te receber. (GUIA, 2017).

O que se observa assim é que o processo turístico se apoia no desenvolvimento de situações que obedecem a uma lógica organizacional que se propõem a criar mecanismos de mensuração e consequente controle administrativo.

Dessa realidade pode-se questionar: A Feirinha da Liberdade é interessante de se visitar também durante a semana? Como caracterizar as denominadas "comidinhas nipônicas"? O que efetivamente seriam? O que se nota são particularidades descritivas, no caso do GUIA (2017), que se amparam em uma memória coletiva não institucionalizada, ou seja, aquilo que o imaginário popular, influenciado por inúmeros elementos escolheu para ser representado.

O bairro da Liberdade cuja sua evolução histórica vinculou-se a ser o local inicial de permanência da etnia japonesa acabou por ter essa característica reproduzida constantemente como forma de criar elementos estruturais de uma memória necessária a servir grupos sociais hegemônicos, que desta forma legitimamse no poder. Bairros étnicos são turísticos, mas também não devem ser esquecidos, pois nasceram como espaços de segregação de minorias. A perpetuação desses modelos, legitimados pelas práticas turísticas garantem a continuidade do fenômeno turístico, além de sua massificação, comercialização e estruturação.

\section{CONSIDERAÇÕES FINAIS}

A relação de identificação do turista com o local de visitação pode acontecer por inúmeros fatores, fato que qualifica o turismo como um fenômeno social, político 
e econômico. O uso do patrimônio cultural constituído mostra que é possível de se estabelecer uma identicidade para o local que pode ter vínculos, ou não, com seu processo de desenvolvimento histórico. No caso do bairro da Liberdade, o fator preponderante encontra-se em buscar uma expressão de pertencimento em modelos artificialmente construídos, mas associados diretamente em um imaginário formativo do local.

O bairro da Liberdade na atualidade ainda preserva lembranças significativas dessa realidade turística desenvolvida, com processos artificialmente induzidos a partir daquilo que a memória coletiva local elegeu para ser uma espécie de representação da realidade do espaço habitado. A manutenção do modelo demonstra que seu uso é viável econômica e socialmente ao responder com resultados que incorporam usos e funções organizadoras do fenômeno turístico local.

\section{REFERÊNCIAS}

ARAUJO, O. E. Enquistamentos Étnicos. Revista do Arquivo Municipal, São Paulo, n. LXV, p. 227-249, 1940.

BOCCI, D. S. Bairro da Liberdade e a imigração japonesa: a ideia de Bairro Japonês. São Paulo, 2008. Disponível em<http://www4.pucsp.br/revistacordis/ downloads/numero2/revista_cordis2_diego_pesquisa.pdf $>$ Acesso em: 26 jun. 2017.

BRUNO, E. S. História e tradições da cidade de São Paulo. Rio de Janeiro: José Olympio, 1953.

CAVENAGHI, A. J. O território paulista na iconografia oitocentista: mapas, desenhos e fotografias. Análise de uma herança cotidiana. Anais do Museu Paulista, v. 14, p. 195-241, 2006.

DICK, M. V. P. A. A dinâmica dos nomes na cidade de São Paulo (1554-1897). São Paulo: ANNABLUME, 1997.

GUIA da cidade de São Paulo. Prefeitura Municipal, 2017. 
GUIMARÃES, L. B. M. História dos bairros de São Paulo: Liberdade. São Paulo, 1968.

ISSA, Y.; DENCKER, A. Processos de Turistificação: Dinâmicas de inclusão e exclusão das comunidades locais. Caxias do Sul, 2005.

LEMOS, C. O que é patrimônio histórico. São Paulo: Brasiliense, 1989.

OSAKI, M. História dos bairros de São Paulo: Liberdade, 2008. Disponível em: $<$ https://www.youtube.com/watch?v=fOqWNtnxp1w\&t=765s $>$. Acesso em: 26 jun. 2017.

Recebido em: 20/06/2018 Aceito em: 14/11/2018 